\title{
Ethological and biological features of the organism of the black- and-white bulls when using natural feed additives in the diets
}

\author{
Oksana Krasnova ${ }^{1}$, Ekaterina Hardina ${ }^{1 *}$, Sergei Hramov ${ }^{1}$, Michail Kudrin ${ }^{1}$, and Nina Konik ${ }^{2}$ \\ ${ }^{1}$ Izhevsk state agricultural academy, 426069 Izhevsk, Russia \\ ${ }^{2}$ Saratov state agrarian University named after N. I. Vavilov, 410012 Saratov, Russia
}

\begin{abstract}
The authors studied the natural feed additive effect to the behaviour and biochemical blood composition of the black-and-white bulls. As results of the scientific experiment we came to the conclusion that using of the biologically active substance dihydroquercetin as a part of a natural feed additive in livestock feed for the metabolic processes intensity stimulation, the nutrient synthesis intensity and higher rates meat productivity formation.
\end{abstract}

\section{Introduction}

New animals genotypes created in the past few decades by breeders in many countries of the world have a rather high potential for productivity and are intended for livestock products intensive production. The inadequate state of the animal habitat and the poor technology conditions often impede the full realization of these genetic possibilities. It is necessary to take in mind the fact that the process of animal breeding is primarily aimed at increasing the productivity and products quality, which greatly weakens the organism protective functions, were developed during the evolution of a particular species. This circumstance leads to the fact that new animals genotypes are particularly demanding on feed quality, the feed ration structure and the nutrients range that provide the organism physiological need, both under normal conditions and taking in mind the action of different etiology stress factors [1,2].

In current moment, the feed and feed mixtures that actively used in the livestock feeding cannot always satisfy nutrients and energy physiological need [3]. Improving the organism resistance to the technological and environmental factors as well as productive health and longevity of full-aged animals is possible when during feed rations preparing takes in mind natural essential compounds [4-6]. The natural essential compounds group is quite numerous and represented mainly by vitamins and bioflavonoids such as inositol, choline, carnitine, vitamin P. It is worth noting that bioflavonoids are more promising natural factors for animal nutrition using [7].

In the last decade, the dominant component of the diquertin bioflavonoid complex the dihydroquercetin which is extracted from the butt part of the Daur larch is quite interesting. This bioflavonoid has a wide range of biological effects for organism, regulating metabolic processes, creates mechanisms for cells protecting and cell structures from pathologies of various genesis. Dihydroquercetin recognized as a reference antioxidant and used is especially relevant at livestock breeding in territories of heavy metals and radionuclides. In modern cattle breeding, much attention paid to the provision of animal's balanced nutrition. It is possible to increase the animal's productivity and effectively feed conversion while using scientifically based feeding systems.

Today, highly productive animals are observed with unnaturally intensive metabolism, increased requirements for the quality of feed and the full value of feeding $[8,9]$. In the feeding process, the compound substances that affect the animal's organism are not isolated from each other. In order to increase the productive effect of feeds it is recommended to enrich them with biologically active substances, which significantly increases their rational use [10, 11]. Local and foreign experience of biologically active substances in animal husbandry convinces us that a promising direction is the use of natural compounds that have a wide range of action and lack a number of shortcomings $[12,13]$.

Among the natural compounds that attract the attention of many scientists, include the reference bioflavonoid - dihydroquercetin (DKV). This substance is isolated from the cell panels of Siberian and Dahurian larch. Dihydroquercetin is a natural antioxidant. It has a high activity even at low concentrations in the range $0.0001-0.00001 \%$.

The biological properties dihydroquercetin usage is particularly relevant for the production of livestock products. The available data of dihydroquercetin antioxidant usage in cattle feed rations diets require clarification, since the scientific basis for the effectiveness of its application in the milk and beef production technology has not been sufficiently studied. An investigation of the DKV effect at the cattle

* Corresponding author: chydo.izhevsk@ rambler.ru 
organism in general and, in particular, at animals' productivity is relevant $[14,15]$.

Antioxidants usage, which makes an important and multifaceted role in the animal live, is a new direction in cattle husbandry. The results of local and foreign studies indicate that the antioxidants usage in animal husbandry allows more efficient feed nutrients usage and lower feed costs per one production item $[16,17]$. The antioxidants adding into the mixed feed contributes to the reduction of oxidative processes in the organism, ensures young animals low mortality, increases their live body-weight, general resistance and animals productivity [18]. Due to this, the need for a deep studying of the antioxidants effect at the metabolism and animal's productivity including cattle husbandry have a big theoretical and practical importance.

In animal husbandry practice ethology is particular importance - the science, covering general biology, physiology, biochemistry and zoo-psychology. Based on knowledge of ethology, behavior forms and patterns, nervous system features functioning identified and become possible to control their behavioral responses [19, 20].

Since the specific animal's conditions and existing technological approaches are reflected in the manifestation of a certain productivity level, irreplaceable and accurate ways to determine the metabolism intensity and their ability to be adapted to the technology changing conditions of maintenance and feeding, are the study of behavioral reactions of animals and blood picture analysis [21, 22].

\section{Material and methods}

Due to that in the conditions of the existing farm in the Udmurt Republic done scientific and economic research for natural feed supplements effect studying. Feed was enriched with bioflavonoid dihydroquercetin and during the research analyzed black-and-white breed bull's behavior and the blood biochemical composition.

According to the principle of analogs group, 20 animals fattening black-and-white breed bull's selected at the age of 3 months, taking in mind body weight, body composition and health status. The animals formed two groups with 10 animals each: the control group and the experimental one. Experimental animals were in similar conditions and feeding. Feed rations balanced in accordance with detailed norms. Based on the developed feeding scheme the experimental group bulls received natural basic feed ration enriched with dihydroquercetin. From the age of 3 months to 17 months, the feed daily included dihydroquercetinonce a day in the morning feeding.

The composition of the natural feed additive is salt, dihydroquercetin (the amount of the main substance is $92 \%) .1 \mathrm{~kg}$ of natural feed supplement contains 2.5 grams of bioflavonoid (dihydroquercetin).

The behavior of fattening bulls studied in the following periods: 3, 6, 9, 12 and 15 months in accordance with the method of V.I. Velikjanin (1975). At the same time, timekeeping performed during the day using the alphabet of basic behavioral reactions.
According to the timing of the duration of the main behavioral acts were calculated indexes of total activity (ITA) and food activity index (FAI).

The control of the physiological processes in the organism of fattening bulls was carried out based on the biochemical determination the concentrations of substances studying. The research done in the Izhevsk State Agricultural Academy at the interdepartmental biotechnology laboratory using the semi-automatic biochemical analyzer for clinical biochemistry "Stat Fax 1904 +" according to the methods specified with the reagents used for using the methods of semi-automatic biochemical analyzer for clinical biochemistry.

The animal's blood samples carried out in age periods: $3,6,9,12,15$ months. The biochemical composition of blood studied according to the following indicators: total protein content $(\mathrm{g} / \mathrm{l})$, cholesterol $(\mathrm{mmol} / \mathrm{l})$, alkaline phosphatase (E/l), alanine aminotransferase (E/l), and aspartate aminotransferase (E/l).

The research results were processed biometrically using the methods of variation statistics using personal computers and Microsoft Office 2003-2007 programs; Microsoft Office Word and Microsoft Office Excel.

In the biometric processing of the experiment the arithmetic mean and error were determined, the criterion for the reliability of the difference in the mean indices for the group (td) and the significance level (p) for the Student-Fisher, for which the following notations were adopted as: * $-\mathrm{P} \geq 0.95 ; * *-\mathrm{P} \geq 0.99, * * *-\mathrm{P} \geq 0.999$ (NA Plokhinsky, 1961, EK Merkuryeva, 1983).

\section{Results}

In ethological studies, the special attention paid to the organism behavior as a whole for clarifying the links between various behavior forms and productivity. Conducting animal chronometry in combination with taking into mind the duration and volumes of feed consumed makes it possible to obtain material for determining the speed of feed consumption, the time spent by animals for eating and chewing, the duration and number of ruminants, as well as the interval from feeding to the chewing appearance. The animals feeding behavior knowledge, their relationships in a group, breed and age behavior characteristics is necessary for the proper feeding and maintenance organization [23].

The analysis and assessment for the natural feed supplement influence degree enriched with dihydroquercetin to the bulls behavioral reactions revealed significant intergroup differences in the animals behavior at the age of 9, 12, and 15 months (Fig 1,2).

During assessing the intergroup differences in the bulls behavior at the age of 9 months against the background using the feed additive found that the experimental group bulls spent more time in the standing position relative to the control group for 105 minutes (18.7 \%) $\quad(\mathrm{P}<0.001)$, more time spent for feed consumption- by 40.7 minutes $(11.3 \%)(\mathrm{P}<0.05)$. The experimental group bull respectively spent less time in the lying position relative to the control group at 105.2 minutes $(10.7 \%)(\mathrm{P}<0.001)$ and spent more time for 
sleeping by 9.8 minutes $(2.6 \%)$. At the same time, the indexes of total (0.513) and food activity (0.424) in the experimental group bulls relative to the control group prevailed by 17.2 and $6.5 \%$, respectively. The intergroup differences trend persisted at the 12 months age.

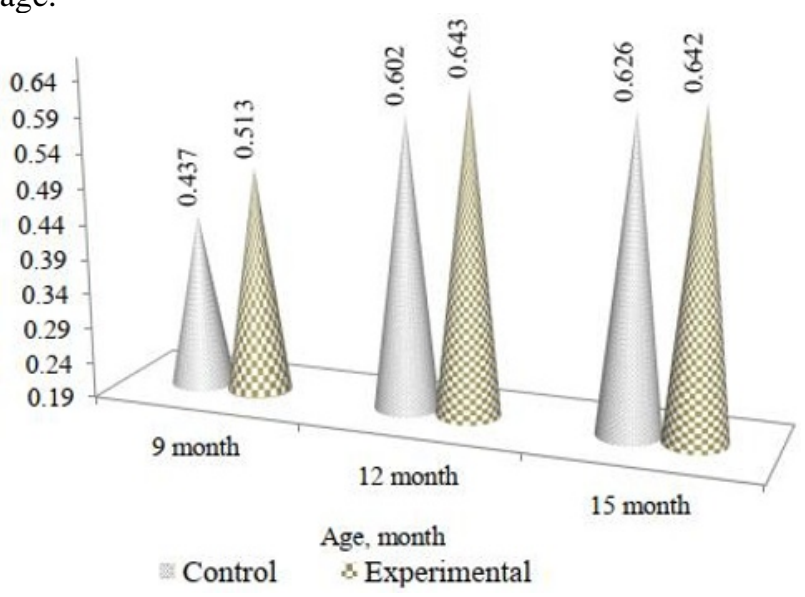

Fig. 1 Indexes of total activity (ITA)

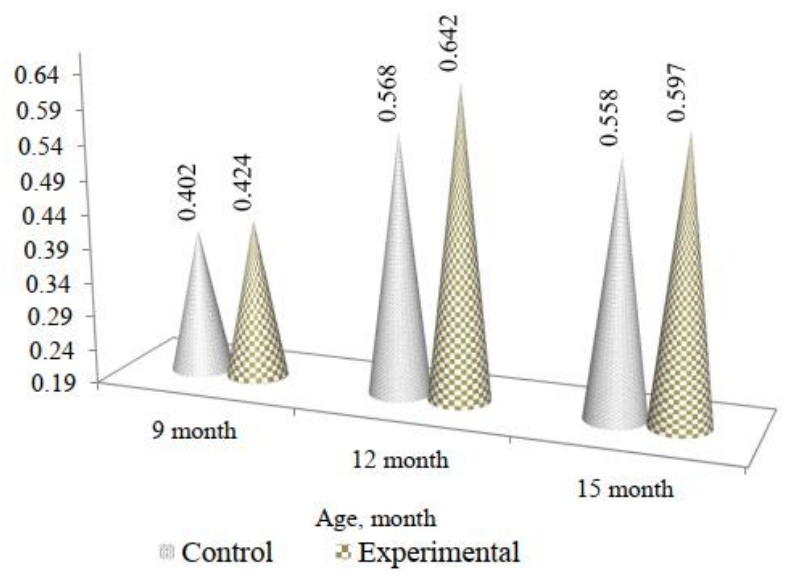

Fig. 2 Food activity index (FAI).

At the age of 15 months detected that the experimental group bulls for 47 minutes (8.7 \%) $(\mathrm{P}<0.05)$ were less standing, relative to the control group, 18.8 minutes more spent time for feed consumption and 39.1 minutes $(9.6 \%)(\mathrm{P}<0.001)$ is more on chewing at the prone position. Accordingly, the experimental group bulls spent more time in the prone position relative to the control group counterparties for 47 minutes $(4.9 \%)(\mathrm{P}<0.05)$.

Bull's behavioral reactions manifestations reflected in the calculation total and nutritional activity indexes. The experimental group bulls had the highest total (0.642) and nutritional activity (0.597) indexes compared with the control group bulls by 2.5 and $6.5 \%$ respectively.
Since behavioral reactions are the animal kind of response to the changing feeding conditions and maintenance then similar changes could be recorded as studying the biochemical blood structure.

Biochemical blood structure is a clinical test for all organ systems functional state [24]. Blood serum composition biochemical research revealed that the allexperimental group's bulls in the period up to age of 15 months increased the content of total protein in the blood serum (Table 1).

At the age of 9 months, the protein amount in blood serum at the experimental group was $66.6 \mathrm{~g} / \mathrm{l}$, which is $1.6 \%$ higher than the control group. At the age of 15 months the protein amount in the bull's blood serum in the experimental group was $76.6 \mathrm{~g} / \mathrm{l}$, and the intergroup difference parameter was $2.14 \%$ ( $\mathrm{P}<0.001)$.

The enzyme alkaline phosphatase high activity as a rule is observed in the period of intensive animal growth and decreases significantly with the age of maturity. The alkaline phosphatase level in bull's blood samples in the experimental groups increases directionally to 9 months of age. Thus, at the age of 9 months the enzyme concentration in the experimental bull's blood of all groups was within 258.9-278.2 U/l, at the age of 12 months a decrease in alkaline phosphatase was noted, its level was within 206.0-210.7 U/l.

At the age of 15 months tendency to decrease in this enzyme in the serum remains. In the intergroup differences, analysis at the age of 9 months found that serum alkaline phosphatase in the serum of the experimental group was $4.5 \%$ higher than in the control group. The enzymes activity the alanine aminotransferase (AlAt) and aspartate aminotransferase (AsAt) is a specific marker of the functional state of the cardiovascular system and the liver. In the blood serum, that represent the microsomal fraction and activity in creasing is characteristic of dysfunctions in the cardiovascular system and is associated with various etiologies hepatitis [25].

During the analysis of the enzymatic AsAt and AlAt activity tended to decrease in the experimental group animals blood the relative to the control group. At the age of 12 months a significant decrease in the level of AlAt in the blood serum of the experimental group bulls compared to the control group by $5.5 \%(\mathrm{P}<0.05)$ was found. By the age of 15 months, the trend persists and the level of AsAt and AlAt in the experimental group was $74.8 \mathrm{U} / 1$ and $15.8 \mathrm{U} / 1$, which is $1.7 \%$ and $7.6 \%$ lower than the control group, respectively. This fact indicates the protective drug effect to the myocardium cardiomyocytes and liver hepatocytes. 
Table 1. Biochemical composition of blood serum of experimental animals

\begin{tabular}{|c|c|c|c|c|c|c|}
\hline \multirow{2}{*}{ Groups } & \multicolumn{7}{|c|}{ Indicator } \\
\cline { 2 - 6 } & Total protein content, g/l & Cho-lesterol, mmol/l & Alkaline phosphatase, E/l & AlAt, E/l & AsAt, E/l \\
\hline \multicolumn{7}{|c|}{3 months } \\
\hline Control & $59.3 \pm 1.5$ & $2.4 \pm 0.15$ & $180.8 \pm 5.47$ & $35.0 \pm 1.04$ & $70.5 \pm 1.61$ \\
\hline Experi-mental & $60.7 \pm 0.4$ & $2.1 \pm 0.2$ & $179.2 \pm 4.84$ & $34.9 \pm 1.23$ & $70.1 \pm 1.53$ \\
\hline \multicolumn{7}{|c|}{6 months } \\
\hline Control & $63.1 \pm 0.28$ & $2.4 \pm 0.23$ & $209.8 \pm 5.32$ & $31.1 \pm 1.08$ & $69.0 \pm 4.18$ \\
\hline Experi-mental & $65.8 \pm 0.57^{* * *}$ & $2.2 \pm 0.35$ & $229.4 \pm 6.41^{*}$ & $30.5 \pm 1,5$ & $63.2 \pm 1.75^{*}$ \\
\hline \multicolumn{7}{|c|}{9 months } \\
\hline Control & $65.5 \pm 0.63$ & $3.2 \pm 0.65$ & $258.9 \pm 5.28$ & $30.6 \pm 2.64$ & $64.7 \pm 4.84$ \\
\hline Experi-mental & $66.6 \pm 0.81$ & $2.9 \pm 0.61$ & $278.2 \pm 5.98^{* *}$ & $30.4 \pm 2.82$ & $62.9 \pm 4.1$ \\
\hline \multicolumn{7}{|c|}{12 months } \\
\hline Control & $69.1 \pm 1.8$ & $2,6 \pm 0.24$ & $206.0 \pm 5.16$ & $25.7 \pm 0.6$ & $70.3 \pm 4.75$ \\
\hline Experi-mental & $73.6 \pm 1.23^{*}$ & $2.4 \pm 0.27$ & $210.7 \pm 4.46$ & $24.3 \pm 0.2^{*}$ & $64.8 \pm 5.25$ \\
\hline \multicolumn{7}{|c|}{15 months } \\
\hline Control & $75.6 \pm 0.35$ & $3.3 \pm 0.34$ & $194.6 \pm 3.7$ & $17.1 \pm 1.51$ & $76.1 \pm 1.97$ \\
\hline Experi-mental & $76.6 \pm 0.28^{* * *}$ & $3.1 \pm 0.41$ & $203.7 \pm 4.2^{*}$ & $15.8 \pm 1.71$ & $74.8 \pm 2.13$ \\
\hline
\end{tabular}

$*_{-} \mathrm{P} \geq 0.95 ; *_{-} \mathrm{P} \geq 0.99 ; * *_{-} \mathrm{P} \geq 0.999$.

\section{Conclusion}

Thus, a black-and-white bulls the application to the feed diet the natural feed additive did not cause negative reactions from the nervous system which confirmed by the research. The experimental group animals spent more time consuming, chewing food and resting. The positive behavioral activity dynamics to the experimental group animals was reflected in the metabolic processes intensity and the nutrient synthesis intensity, as evidenced by the experimental group samples positive serum levels, total protein, alkaline phosphatase and the enzymatic activity of AsAt and AlAt.

Based on the obtained results analysis and evaluation we recommend natural feed additive enriched with dihydroquercetin daily single using in the technological cycle for the growing and fattening bulls.

The studies carried out have made it possible to determine the positive dihydroquercetin effect to the different metabolic processes in the animal's organism, the intensity of their growth, the meat productivity of fattening bulls, cow-heifers milk productivity and the milk quality. The obtained results confirmed dihydroquercetin advisability using in black-motley breed cattle feed rations.

Taking into consideration very small dihydroquercetin dosage this natural feed supplement can be used in animal daily feeding rations without hindering specialists from their work. The functionality of the natural feed additive with dihydroquercetin is quite high; this is confirmed by the results of the second and third scientific research stages.

\section{Acknowledgements}

The work was supported by the cows farm "Kigbaevo Agro". The studies have been conducted with the scientific support of the staff of Animal Husbandry and Medicine faculties of the Izhevsk state agricultural academy.

\section{References}

1. N.M. Kostomahin, A.V. Hovankina, Main lives., 10, 3-13 (2017)

2. Eh.M. Mulangi, I.P. Prohorov, A.N. Pikul', Bullet. of agricult. Sci., 6-69, 77-82 (2017)

3. M. Florek, P. Stanek, Z. Litwińczu, P. Żółkiewski, Bulg. J. of Agr. Sci., 19-5, 1112-1119 (2013)

4. L.N. Gamko, A.N. Gulakov, E.V. Novikova, A.A. Ryazhnov, Tauride sci. Obs., 5-2(10), 106-110 (2016)

5. S. Mc. Namara, J. of Dairy Sci., 86, 2397-2408 (2003)

6. M.B. Ulimbashev, Bull. of the Rus. Acad. of agric. Sci., 6, 76-78 (2008)

7. K.H. Wagner, An., Nut. and Metab., 48, 169-188 (2004)

8. D.T. Juniper, J. of Anim. Sci., 86, 3100-3109 (2008)

9. O.A. Krasnova, M.I. Vasilyeva, Young Sci. USA Raleigh, 3-6 (2015)

10. Ceballos-Marques, J. of Dairy Sci., 93, 4602-4612 (2010)

11. K. P.Waller, J. of Dairy Scien. 90 3640-36 (2007).

12. P. Dobbelaar, J. of Dairy Sci., 93, 3103-3113 (2010)

13. R.R. Fatkullin, A.A. Ovchinnikov, E.M. Ermolova, Y.V. Matrosova, S.A. Chulichkova, Int. J. of Eng. and Tech., 7-3(14), 300-304 (2018)

14. J.D. Arthington, J. of Anim. Sci., 86, 1472-1477 (2003)

15. K. Holtenius, J. of Dairy Sci., 86, 883-891 (2003)

16. G.R. Beecher, J. of Nutr., 133, 3248-3254 (2003)

17. A. Brigelius-Flohe, J. of Clinic. Nutr., 76, 703-716 (2002)

18. O.A. Krasnova, E.V. Hardina, Bullet. of Bashkir st. agr. Univer., 3-39, 49-51 (2016) 
19. E.A. Maksim, N.A. Yurina, S.I. Kononenko, Collect. of scient. works of the all-Rus. Res. Ins. of sheep and goat breeding, 1-9, 106-109 (2016)

20. P.G. Pietta, J. of Nat. Prod., 63, 1035-1042 (2000)

21. A.F. Shevkhuzhev, A.I. Dubrovin, M.B. Ulimbashev, R.A. Ulimbasheva, New. of Orenb. St. agr. Univer., 1-57, 64-66 (2016)

22. C.R. Stockdale, C.R. Gillt, J. of Dairy Sci., 94, 2351-2359 (2011)
23. A. Stimbirys, L. Shernienè, V. Prusevichus, V. Jukna, Al. Shimkus, Al. Shimkenè, Bulg. J. of Agr. Sci., 22-4, 627-634 (2016)

24. A.F. Shevkhuzhev, M.B. Ulimbashev, I.K. Taov, O.O. Getokov, E.R. Gosteva, Res. J. of Pharm., Biolog. and Chemic. Sci., 8-6, 591-596 (2017)

25. R.V. Nekrasov, N.I. Anisova, A.S. Anikin, M.G. Chabaev., All-Rus. Sci. res. Ins. of livestock RAAS, 67 (2013) 